\title{
Drosophila Models of Neurodegenerative Disease
}

\author{
Tzu-Kang Sang and George R. Jackson
}

\begin{abstract}
Neurogenetics Program, Department of Neurology, Brain Research Institute, Center for Neurobehavioral Genetics, Neuropsychiatric Institute, David Geffen School of Medicine at UCLA, Los Angeles, California 90095
\end{abstract}

\begin{abstract}
Summary: Over the last two decades, a number of mutations have been identified that give rise to neurodegenerative disorders, including familial forms of Alzheimer's disease, Parkinson's disease, and amyotrophic lateral sclerosis. Although in most cases sporadic cases vastly outnumber familial forms of such diseases, study of such inherited forms has the potential to provide powerful clues regarding the pathophysiological basis of neurodegeneration. One powerful approach to analyzing disease mechanisms is the development of transgenic animal models, most notably in the mouse. However, development and analysis of such models can be costly and time consuming.
\end{abstract}

Development of improved transgenic technologies have contributed to the development of Drosophila models of a number of neurodegenerative disorders that have shown striking similarities to the human diseases. Moreover, genetic screens using such models have begun to unravel aspects of the pathophysiological basis of neurodegenerative disorders. Here, we provide a general overview of fly models pertinent to trinucleotide repeat expansion disorders, Alzheimer's, and Parkinson's diseases, and highlight key genetic modifiers that have been identified to date using such models. Key Words: Drosophila, transgenic animal, polyglutamine, tau, $\alpha$-synuclein.

\section{INTRODUCTION}

What can Drosophila models contribute to our understanding of neurodegenerative disorders? Even 10 years ago, most academic neurologists and neurobiologists would have answered, "Nothing," and this would have been not far from the truth. However, recent advances in our understanding of the molecular basis of neurodegenerative disease and Drosophila genetics have enabled engineering of the simple fruit fly to create models that have shed light on the pathophysiological basis of neurological disorders afflicting humans. Considerable advances have also been made in study of learning, memory, and circadian rhythms that are of great interest; however, these will not be reviewed here. Rather, this review will focus on a number of studies that have employed targeted misexpression of human disease-associated proteins to model trinucleotide repeat expansion disorders, Alzheimer's disease (AD), and Parkinson's disease (PD). This is not intended to be a comprehensive view because this field has expanded considerably; rather, the reader without a background in fly genetics should be able to appreciate the contributions that fly

Address correspondence and reprint requests to George R. Jackson, 4357C Gonda Center for Neuroscience and Genetics, 695 Charles E. Young Drive South, Los Angeles, CA 90095. E-mail: grjackson@mednet.ucla.edu. models in general have made to our understanding of neurodegenerative disorders. We will also briefly consider reverse genetic approaches that have targeted fly homologs of human neurodegenerative disease-associated genes.

\section{GENETIC APPROACHES TO STUDY OF NEURODEGENERATION}

Three quarters of the approximately 100 genes implicated in specific human diseases have at least one homolog in Drosophila. An online database of on human disease genes with fly homologs is available (http:// superfly.ucsd.edu/homophila/).

Homologs of human neurodegenerative disease genes disease genes can be identified in the Drosophila genome. The function of these genes can then be studied by generating mutations in the Drosophila homolog and then studying the resulting phenotypes (if any). Just such an approach has recently been applied to study the fly homologs of ataxin-2, the gene mutated in spinocerebellar ataxia $2,{ }^{1}$ and in parkin, ${ }^{2,3}$ a gene associated with autosomal recessive juvenile parkinsonism (discussed in more detail below). Studies of the fly homolog of atrophin, a gene in which a CAG expansion gives rise to dentatorubral pallidoluysian atrophy (DRPLA), have revealed its role as a transcription factor. ${ }^{4}$ An alternative 
approach uses RNA interference-mediated knock down of gene expression. Such an approach has identified a role for the fly homolog of huntingtin in regulation of axonal transport and cell death. ${ }^{5}$

\section{WHY STUDY NEURODEGENERATION IN FLIES?}

A pathogenic process of interest in humans can be studied in flies if it can be recapitulated in a manner showing characteristics similar to those observed in man. If so, genetic approaches can be applied to order to study this pathogenic process. Mutations can be generated that affect a relevant pathogenic process without making $a$ priori assumptions about pathways involved. This potential of genetic approaches to elucidate pathogenic processes makes flies such a powerful model system in neurobiology.

\section{HOW SIMILAR ARE FLIES AND HUMANS?}

Implicit in studies of invertebrate models of neurodegenerative disorders is the assumption that essential features underlying biology of humans and flies are conserved. How similar are humans and Drosophila? Generally speaking, fundamental aspects of cell biology are quite similar in man and flies, including regulation of gene expression, membrane trafficking, the cytoskeleton, neuronal connectivity, synaptogenesis, cell signaling, and cell death. Many genes and pathways that originally were studied in flies have subsequently been identified in mammals. As an example, the wingless pathway in Drosophila was named for a mutation originally identified in a spontaneously occurring mutant that was noted to have no wings. ${ }^{6}$ The mammalian homolog of the Drosophila wingless gene, Wnt, is now known to stand at the apex of the Wnt pathway also conserved in mammals that is crucial for cell polarity, differentiation, and migration, cytoskeletal regulation, synapse formation, and axon guidance during neuronal development. ${ }^{7}$

\section{HOW DIFFERENT ARE FLIES AND HUMANS?}

Of course, there are also important differences between flies and humans that must be borne in mind when interpreting genetic models. As an example, flies have much simpler circulatory systems and cognitive processes. In some circumstances, the relative simplicity of fly as compared with human genomic organization provides benefits with regard to genetic analysis. Often, redundancy exists in humans, where duplicated versions of genes are identified that are present in only one copy in flies; this lack of redundancy can simplify analysis of biological process in the fly. Perhaps the most important aspect of invertebrate approaches is the availability of a number of genetic manipulations that are impossible or impractical to carry out in mammals. Large numbers of flies and worms can be mutagenized and screened in a short period of time, thus permitting the identification of even rare mutations. Given the considerable success that fly genetic approaches have had in delineating processes such as cell cycle control, signal transduction, and pattern formation, it is reasonable to anticipate that similar approaches to the study of neurodegeneration will continue to yield powerful insights into disease mechanisms.

\section{USING THE FLY EYE AS A MODEL}

In 1910, the first Drosophila melanogaster mutant was noticed by an undergraduate dishwasher in the Morgan lab at Columbia who discovered a white-eyed fly among wild-type red-eyed flies. The eye continues to be the focus of research not only because, as Morgan demonstrated, adult eye phenotypes are easy to detect, but also because, unlike most organs in the fly, the eye is tolerant of genetic disruption of basic biological processes. Moreover, under laboratory conditions, the eye is dispensable for survival of the fly. Versatile technologies that can be used to generate, identify, and characterize mutations in the retina have elevated the eye to a system with unrivaled potential for deciphering gene function. A large body of literature indicates the fly eye can be used to study processes including cell cycle control, cell proliferation and differentiation, neuronal connectivity, apoptosis, programmed cell death, and tissue patterning.

\section{TRINUCLEOTIDE REPEAT EXPANSIONS}

\section{Glutamine repeat disorders}

Huntington's disease (HD) is the prototypic disease caused by expansion of unstable CAG repeat, resulting in expression of an expanded polyglutamine tract near the amino terminus of a gene known as huntingtin. ${ }^{8}$ Other diseases in this class include spinocerebellar ataxias (SCA) 1, 2, 3 (also known as Machado-Joseph disease, MJD), 6, and 7, DRPLA, and spinobulbar muscular atrophy (also known as Kennedy's disease). ${ }^{9}$ Table 1 summarizes a number of glutamine repeat disorders that have been modeled in Drosophila. The first neurodegenerative disease model reported in the fly used a fragment of mutant ataxin-3/MJD ${ }^{10}$; this report was followed shortly by a model for HD using fragments of huntingtin. ${ }^{11}$ Other investigators examined the effects of quasi-pure polyglutamine tracts, or polyglutamine tracts expressed within the context of fly genes, such as prospero and disheveled. Models using expression of full-length ataxin-1 and -3 also have been reported.

Figure 1 compares external eye phenotypes and retinal histology in several polyglutamine fly models. Wild-type 
TABLE 1. Summary of Fly Models of Glutamine Repeat Disorders

\begin{tabular}{llc}
\hline Protein Context & \multicolumn{1}{c}{ Repeat Length } & Reference \\
\hline Pure polyglutamine & & \\
& Q48 & 33 \\
& Q108 & 34 \\
& Q63 & 35 \\
& Q79 & 36 \\
& Q92 & 36 \\
Ataxin-1 & & 18 \\
& Full-length Q82 & 37 \\
Ataxin-3 & Full-length Q82 & 38 \\
& Full-length Q82 & 39 \\
Huntingtin & Truncated Q78 & 10 \\
& Full length Q78 & 40 \\
& & 11 \\
& Truncated Q75 (1-171) & 11 \\
& Truncated Q120 (1-171) & 28 \\
& Truncated Q93 (exon 1) & 41 \\
& Truncated Q97 (exon 1) & 41 \\
& Truncated Q103deltaP & 42 \\
Androgen receptor & Truncated Q128 (1-548) & 42 \\
& & Full-length Q52 \\
& Truncated Q52 & 43 \\
& Truncated Q112 & 43 \\
\hline
\end{tabular}

(control) eyes shown normal external morphology of the compound eye, whereas the internal structure shows regular arrays of ommatia, the individual units of the Drosophila retina. Each ommatidium at the level shown contains seven photoreceptor neurons, each of which elaborates a membranous structure, the rhabdomere, which functions in phototransduction. In a normal eye, these rhabdomeres form a characteristic seven subunit chevron-like shape (FIG. 1F). In flies expressing a mutant huntingtin fragment including 120 glutamine residues ("htt-Q120"), appearance of the eye is normal (FIG. 1B), whereas by 10 days after eclosion ("hatching"), disruption of rhabdomere structure and loss of photoreceptor neurons is apparent (FIG. 1G). Expression of the

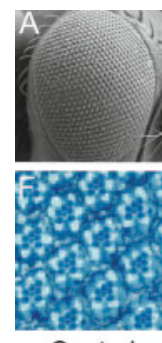

Control

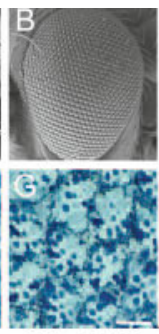

$\mathrm{Htt}-\mathrm{Q} 120$

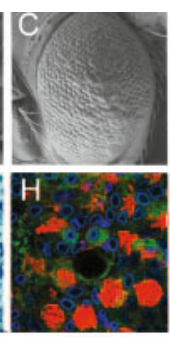

Q108

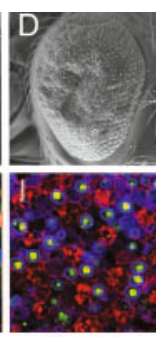

MJD-Q78 Ataxin-1-Q82
FIG. 1. Phenotypes of fly eye models of polyglutamine disease. A-F: SEM images. F and G: toluidine blue-stained tangential retinal sections. $\mathrm{H}-\mathrm{J}$ : confocal images of whole mount retina. $\mathrm{H}-\mathrm{I}$ : red, TRITC-phalloidin; blue, lamin $\mathrm{D}_{0}$. Green: $\mathrm{H}$, htt17, I, anti-HA, J, anti-ataxin-1. Scale bars: A-E, $100 \mu \mathrm{m}$. F-J, $10 \mu \mathrm{m}$.

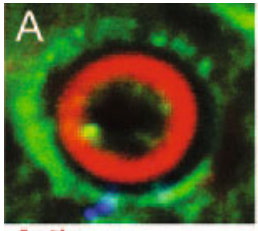

Actin

PolyQ

Ubiquitin

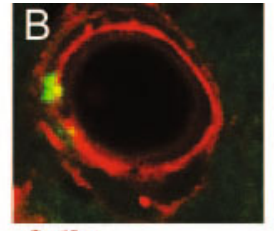

Actin

Ubiquitin

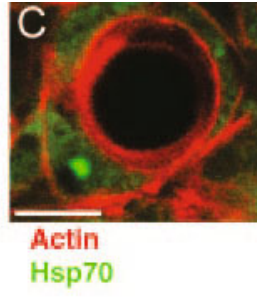

Actin
FIG. 2. Immunostaining of polyglutamine aggregates in adult Q108 retina. Scale bar, $10 \mu \mathrm{m}$.

quasi-pure polyglutamine tract Q108 produces disruption of the external crystalline lattice of the eye, a so-called "rough" eye (FIG. 1C). The internal structure of the retina is completely disrupted, with abnormal rhabdomere remnants and perinuclear and nuclear polyglutamine aggregates. In some cases, multilamellated spherical structures are formed, which are likely to represent autophagosomes (FIGS. 1H and 2). A mutant MJD fragment including 78 glutamine repeats also produced a rough external eye, which tends to collapse under vacuum during scanning electron microscopy (SEM). Internal structure of the retina is disrupted, with formation of intranuclear aggregates. Full-length ataxin- 1 with 82 glutamine residues also produced an abnormal external eye (FIG. 1E), although the internal structure is not very abnormal (data not shown). Figure $1 \mathrm{~J}$ shows the phenotype caused by two copies of the mutant ataxin- 1 transgene, which does produce severe disruption of the retina. In our hands, in the fly retina, unlike mouse, the majority of ataxin-1 is cytoplasmic, although some nuclear aggregates are observed.

Polyglutamine-containing aggregates in mouse and cell models contain a number of additional proteins, including chaperonins and proteasome components. ${ }^{12-16}$ Autophagosome-like bodies in the Q108 model also contain some of these components, as indicated in Figure 2. These structures contain one or more layers of filamentous actin, as indicated by phalloidin staining, as well as polyglutamine and ubiquitin (FIG. 1, A and B). Staining for endogenous fly heat shock protein (hsp) 70 also shows that this chaperonin is present in these aggregates (FIG. 2C).

Both candidate-based and unbiased genetic screens in the fly have begun to identify polyglutamine modifiers. The first of these modifiers to be reported was hsp70; misexpression of a human hsp70, HSPAL, dramatically suppresses the eye phenotype of SCA3 flies. ${ }^{17}$ An unbiased transposon-based screen subsequently identified Drosophila HDJ1, an hsp40; misexpression of HDJ1 dramatically suppressed a quasi-pure polyglutamine phenotype. $^{18}$

Figure 3 compares the effects of misexpression of HSPA1L and HDJ1 on the Q108 eye phenotype. One aspect of the Q108 phenotype that is not apparent using 


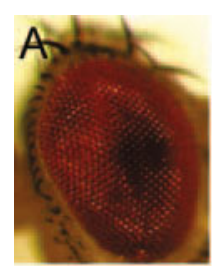

Control

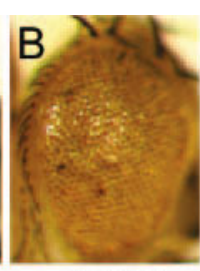

Q108

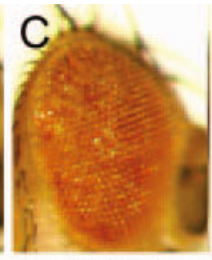

Q108+

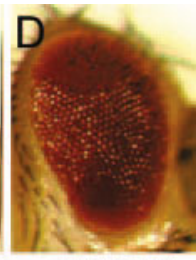

Q108+

HDJ1
FIG. 3. Suppression of $\mathrm{Q} 108$ eye phenotypes by chaperonins.

SEM is severe depigmentation; as compared with control flies (FIG. 1C), the Q108 eye shows, in addition to a rough external appearance, depigmentation (FIG. 3B). Although it is treacherous to evaluate suppression of eye phenotypes based solely on rescue of depigmentation phenotypes (because additional transgenes provide additional pigmentation irrespective of the insert DNA), moderate rescue of pigmentation, as well as improvement in the rough eye phenotype, is observed when HSPA1L is coexpressed with Q108 (FIG. 3C). By contrast, the depigmentation phenotype of Q108 is dramatically suppressed by coexpression of HDJ1 (FIG. 3D). Suppression of the rough external eye phenotype of ataxin-1 by HSPA1L and HDJ1 also has been reported. ${ }^{19}$

The role of apoptotic pathways in cell death in glu-

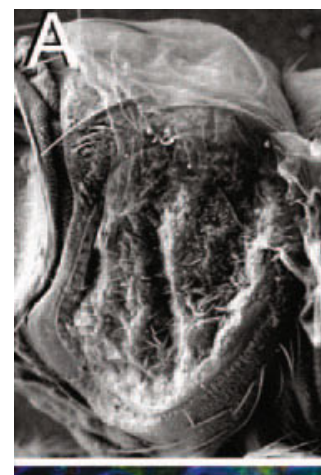

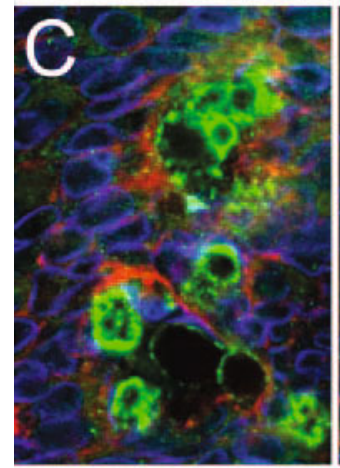

+ ; Q108
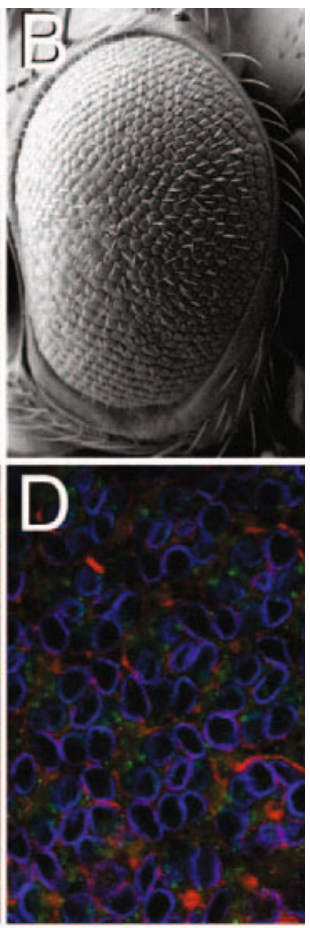

dark; Q108

FIG. 4. Suppression of $\mathrm{Q} 108$ toxicity by homozygous mutation of fly Apaf-1. A and B: SEM images. C and D: Confocal staining of pupal eye (30\%). Red: phalloidin-TRITC. Blue: lamin $D_{0}$. Green: htt17. tamine repeat disorders is controversial; however, in the case of $\mathrm{HD}$, at least, sufficient evidence exists in animal models implicating caspases- 1 and -3 in pathophysiology to support clinical trials of minocycline, an antibiotic with caspase inhibitor activity. ${ }^{20-23}$ In flies, expression of the baculoviral antiapoptotic protein P35 or its fly counterpart, DIAP1/Thread, dramatically suppresses reduced eye phenotypes caused by overexpression of cell death genes. ${ }^{24,25}$ Results of experiments testing suppression of polyglutamine phenotypes in the fly eye have been inconsistent. P35 suppresses ataxin- $1^{19}$ and $-3^{10,19}$ phenotypes, but enhances Q127 ${ }^{19}$ and has no effect on Q108 ${ }^{26}$ or htt-Q120. ${ }^{11}$ Similar patterns are observed for DIAP1: suppression of ataxins-1 and $-3,{ }^{19}$ no effect on Q127 ${ }^{19}$ or Q108 ${ }^{26}$ or htt-Q120 (Salecker, I., and G. R. Jackson, unpublished data). These data suggest that the protein context in which polyglutamine is expressed affect responsiveness to modifiers.

A candidate-based approach examining cell death regulators for modulation of polyglutamine phenotypes revealed striking suppression of Q108 and htt exon1 phenotypes by inactivation of Drosophila Apaf-1, Dark. ${ }^{26}$ Figure 4 compares the effects of homozygous mutation of fly Apaf- 1 on external and internal retinol phenotypes. In a genetic background in which both copies of Dark were mutant, dramatic suppression of Q108 and htt exon1 phenotypes was observed, as well as suppression of caspase activation, cell death, and most surprisingly, aggregate formation. The observation that virtually complete suppression of polyglutamine toxicity in vivo is accompanied by reduced aggregation could be considered evidence that aggregates are toxic, although this is highly controversial ${ }^{27}$ and not likely to be proven or disproven using fly models.

Drosophila models have also proved useful in validation of small molecule compounds predicted to inhibit aggregation based on cell-based studies. Studies of histone deacetylase inhibitors as suppressors of mutant htt exon 1 toxicity in the fly have led to validation in mouse models and clinical trials of phenylbutyrate in $\mathrm{HD}^{28-30}$ Recently, rapamycin has been demonstrated to suppress htt-Q120 toxicity, lending credence for a role of autophagy in polyglutamine disease. ${ }^{31}$ Other studies have identified an inhibitor of the Rho-associated kinase p160ROCK as a suppressor of mutant htt exon1 toxicity in the fly. ${ }^{32}$

\section{Noncoding repeat expansion disorders}

Trinucleotide repeat expansion disorders include, apart from the glutamine repeat disorders already discussed, intronic expansions (e.g., Friedreich's ataxia), as well as noncoding disorders such as SCA8 and myotonic dystrophy. ${ }^{45-47}$ Recently, investigators have begun to use Drosophila to shed light on such noncoding disorders. SCA8 is associated with a CUG repeat expansion within 
a noncoding transcript. ${ }^{46}$ Rebay and colleagues ${ }^{48}$ developed a model of SCA8 in flies that resulted in retinal degeneration, and they isolated RNA binding proteins as modifiers of this phenotype. These findings argue that RNA rather than expanded protein is an effective agent of toxicity. Myotonic dystrophy type I is associated with CTG repeat expansion in the $3^{\prime}$ untranslated region of the dystrophia myotonica protein kinase gene. Monckton and colleagues ${ }^{49}$ developed a model by fusing noncoding CUG repeats to reporter genes and demonstrated that these form ribonuclear foci; however, these repeats were not toxic. Fragile $\mathrm{X}$ syndrome is also associated with noncoding repeat expansion. ${ }^{50}$ In this case, CGG expansion in the $5^{\prime}$ untranslated region of the FMR1 gene leads to transcriptional silencing and loss of expression of Fragile X Mental Retardation Protein. Moses and colleagues $^{51}$ expressed pathological CGG repeats fused to a reporter gene and demonstrated retinal degeneration in the absence of expressed proteins. These findings support the utility of Drosophila in modeling noncoding repeat expansions as well as glutamine repeat disorders, and additional such models are likely to appear in future.

\section{ALZHEIMER'S DISEASE}

\section{Amyloid}

One of the key neuropathological features of Alzheimer's disease is the extracellular amyloid plaque. The main component of these plaques is the $\mathrm{A} \beta$ peptide, which is derived from membrane bound amyloid precursor protein (APP).$^{52}$ APP can be processed by two pathways: the amyloidogenic pathway, which results in production of $\mathrm{A} \beta$, or the nonamyloidogenic pathway, which generates a secreted form of APP. Dominant mutations in APP or presenilins 1 and 2 cause early onset familial Alzheimer's disease. ${ }^{53,54}$ Homologs of APP and presenilin are found in Drosophila. The fly APP homolog, Appl, does not contain the segment of APP cleaved to generate pathogenic peptides. Still, genetic approaches have been informative regarding the role of $\mathrm{Appl}$ in flies. Flies homozygous for large deletions in Appl show defective locomotor behavior, and a human $\beta$-APP transgene rescues this behavior. ${ }^{55}$ A role for Appl in synaptogenesis in flies has been suggested. ${ }^{56}$

Recently, several groups have reported fly models using misexpression of $\mathrm{A} \beta$. Iijima and colleagues ${ }^{57}$ used a signal peptide derived from pre-proenkepahlin fused to $\mathrm{A} \beta$ to generate secreted transgene products. The expression of $\mathrm{A} \beta 42$, the more toxic peptide, led to the formation of diffuse extracellular amyloid, impaired olfactory associative learning, and neurodegeneration. A related group of investigators studied the effects of similar constructs in the eye and demonstrated retinal degeneration. ${ }^{58}$ They also performed a genetic screen and isolated neprilysin 2 as a modifier that suppressed the $A \beta 42$ phenotype when overexpressed. Neprilysin has previously been implicated in $\mathrm{A} \beta$ degradation, ${ }^{59}$ supporting the utility of flies as reagents to identify therapeutic targets. Greeve and colleagues ${ }^{60}$ also have reported retinal neurodegeneration and amyloid plaque-like formation in flies that coexpress APP and either $\beta$-secretase (see below) or a dominant-negative form of presenilin. Goldstein and colleagues ${ }^{61,62}$ have studied impairment of axonal transport by APP in Drosophila, mice, and AD brain.

$\beta$ - and $\gamma$-secretase are responsible for generation of pathogenic $\mathrm{A} \beta$ peptides. Although $\beta$-secretase has been characterized, the proteins responsible for $\gamma$-secretase activity have proved more elusive. ${ }^{52}$ One component of the $\gamma$-secretase complex is presenilin. The Drosophila presenilin homolog, Psn, has been characterized. Mutations give rise to phenotypes reminiscent of Notch mutants. ${ }^{63,64} P s n$ is required for normal proteolytic processing of Notch. Other components of the $\gamma$-secretase complex have been identified using invertebrate approaches, including Caenorhabditis elegans and Drosophila genomics. ${ }^{65}$ These include nicastrin, Aph-1, and Pen-2. Homologs of each are present in Drosophila, and each component appears competent to serve as part of a $\gamma$-secretase complex. ${ }^{66}$ A sensitized genetic system using a GAL4-responsive rough eye phenotype to identify other components of the $\gamma$-secretase complex has been reported. ${ }^{67}$

\section{Tauopathies}

The second key feature of AD pathology is the neurofibrillary tangle (NFT). However, neurofibrillary pathology also is seen in a number of other disorders collectively referred to as tauopathies, including frontotemporal dementia with parkinsonism linked to chromosome 17 (FTDP-17), progressive supranuclear palsy, and corticobasal degeneration. ${ }^{68}$ Tau is a microtubule-associated protein, and its interaction with microtubules is negatively regulated by phosphorylation of sites in or near its microtubule binding repeats. Aberrant regulation of tau phosphorylation, and thus microtubule binding, is thought to occur in tauopathies. Tau hyperphosphorylation is thought to be an early event in the cascade leading from soluble to insoluble tau protein.

Drosophila models of tauopathy have been reported. The fly tau homolog has been cloned and characterized. ${ }^{69}$ Williams and co-workers ${ }^{70}$ found that human tau overexpression in sensory neurons produced a number of abnormal morphologic effects, including axonal loss and swelling. Sensory neurons expressing tau underwent axonal degeneration. More recently, these authors showed that misexpression of a constitutively active form of the tau kinase glycogen synthase kinase (GSK)- $3 \beta$ enhanced impaired axonal transport defects and motor behavior caused by tau. ${ }^{71}$ Wittman and co-workers ${ }^{72}$ overex- 


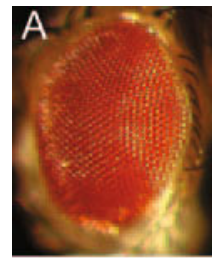

sgg

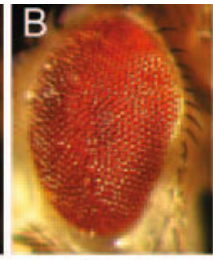

tau

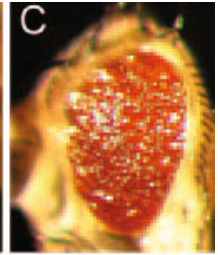

sgg + tau
FIG. 5. Enhancement of the tau eye phenotype by coexpression of Shaggy.

pressed wild type, as well as the FTDP-17-associated mutants R406W and V337M mutant tau in Drosophila CNS. Neuronal loss and vacuolization were observed with both wild type and R406W tau, although pathology was generally more severe with mutant tau. Immunoreactivity for various phosphotau epitopes increased over time. However, no neurofibrillary pathology was observed. Thus, although robust, adult onset, progressive neurodegeneration was observed, the fly model did not show any neurofibrillary changes. When expressed in the retina, a rough eye phenotype was observed with R406W but not wild-type tau; this observation is important because the rough eye phenotype greatly simplifies modifier screens. More recently, tau modifiers recovered from a genetic screen have been reported by Feany and coworkers. ${ }^{73}$ These consist largely of kinases and phosphatases, confirming the importance of phosphorylation of tau in its pathogenicity. However, whether any of these modifiers led to changes in tau phosphorylation or solubility was not reported. Tau misexpression also has been reported to compromise olfactory learning and memory. ${ }^{74}$

Our laboratory has also established models of tauopathy using wild-type ${ }^{75}$ and P301L tau, an FTDP-17-associated mutation (our unpublished data). We have not obtained convincing evidence that mutant tau is more toxic than wild type. Expression of wild-type tau in the eye results in early onset cell death and adult rough eye phenotypes but not the development of any obvious neurofibrillary pathology. However, coexpression of Shaggy (Sgg), the fly homolog of the tau kinase GSK-3, enhances tau toxicity dramatically. Figure 5 compares the effects of expression of Sgg, tau, and the synergistic effects obtained when the two are coexpressed. Panneural expression of Sgg alone has no effect on external eye phenotype (FIG. 5A). Wild-type tau alone produces a mild rough eye phenotype when expressed throughout the retina (FIG. 5B); however, dramatic synergy is observed when tau and Sgg are coexpressed, resulting in a severely rough eye (FIG. 5C). Expression of the NFTrelated phosphoepitope AT100 is observed in dual tau + Sgg transgenics, and insoluble filamentous materials, including straight and paired helical filaments, are observed. These observations support the contention that phosphorylation of tau leads to formation of NFT in vivo.
Others have confirmed the enhancement of tau pathogenicity by Sgg coexpression and have suggested that phosphorylation by the kinase PAR-1 is required for subsequent phosphorylation by other kinases such as GSK-3. ${ }^{76}$

\section{PARKINSON'S DISEASE}

\section{$\alpha$-Synuclein}

Parkinson's disease is an idiopathic disorder featuring resting tremor, rigidity, bradykinesia, and postural instability. Pathologically, it is associated with degeneration of nigral dopamininergic neurons and formation of neuronal Lewy bodies, eosinophilic cytoplasmic inclusions containing $\alpha$-synuclein. Although the true prevalence of all inherited forms of Parkinson's disease is unclear, rare cases of dominant PD have been associated with missense mutations in $\alpha$-synuclein. ${ }^{77}$ More recently, genomic triplication of the $\alpha$-synuclein locus has been associated with dominant parkinsonism. ${ }^{78}$ Feany and Bender $^{37}$ described a fly model of Parkinson's disease using misexpression of wild-type and mutant $\alpha$-synuclein. Both wild-type and mutant forms of $\alpha$-synuclein induced loss of tyrosine hydroxylase-immunoreactive neurons in the central brain of the fly, as assessed using immunohistochemistry of paraffin sections. Intracytoplasmic and neuritic accumulation of $\alpha$-synuclein was observed, suggestive of Lewy bodies and Lewy neurites, respectively. Both wild-type and mutant $\alpha$-synuclein resulted in progressive motor impairment. Very mild retinal degeneration was reported in aged flies expressing wild-type $\alpha$-synuclein.

Bonini and colleagues ${ }^{79}$ examined effects of chaperonin misexpression on $\alpha$-synuclein phenotypes in Drosophila. They were unable to demonstrate abnormal motor behavior in flies expressing $\alpha$-synuclein. These authors reported that overexpression of HSPA1L partially rescued dopaminergic degeneration induced by $\alpha$-synuclein without affecting the appearance of $\alpha$-synuclein-containing inclusions. A transgene encoding a dominant negative version of a constitutively expressed Drosophila hsp70 enhanced $\alpha$-synuclein-induced degeneration. Of interest, this transgene when overexpressed in dopaminergic neurons itself had negative effects independent of $\alpha$-synuclein, suggesting that endogenous chaperonin activity regulates survival of dopaminergic neurons. Bonini and Auluck and colleagues ${ }^{80,81}$ also showed that feeding flies with geldanamycin, which acts to upregulate chaperonins, also protected against $\alpha$-synuclein-induced toxicity in dopaminergic neurons.

A number of additional papers have reported chemical and genetic modifiers of $\alpha$-synuclein toxicity in Drosophila. ${ }^{82-84}$ However, the significance of the $\alpha$-synuclein model has been called into question by recent work by Mardon and colleagues, ${ }^{85}$ who used whole mount confocal analysis 
of tyrosine hydroxylase staining in brain and were unable to demonstrate any neurodegeneration using a number of different $\alpha$-synuclein lines. Nor were these authors able to demonstrate any abnormal behaviors or retinal degeneration induced by $\alpha$-synuclein. It is possible that variations in food or environment are responsible for these variations in $\alpha$-synuclein toxicity from lab to lab.

\section{Parkin}

The identification of mutations in parkin associated with autosomal recessive juvenile parkinsonism (ARJP) ${ }^{86}$ has provided new insights into the pathogenesis of both sporadic and familial forms of PD. Point mutations, deletions, and compound heterozygosity for mutations have been identified. ${ }^{87}$ Studies of genetically derived animal models have attempted to define the relationship between parkin mutations and survival of dopaminergic neurons. However, with the exception of cell loss in locus coeruleus in one knockout, ${ }^{88}$ loss of function studies of parkin in mouse have failed to produce robust cell loss. ${ }^{89-91}$ A homolog of parkin exists in Drosophila. Pallanck and colleagues ${ }^{2}$ reported that parkin mutations in the fly cause cell death of sperm and indirect flight muscles. Marden and co-workers ${ }^{3}$ independently generated loss of function mutations and also found that these lead to reductions in cell size and increased susceptibility to oxidative stress. However, neither of these groups of investigators demonstrated that parkin mutations affect survival of DA neurons.

\section{SUMMARY AND PERSPECTIVES}

Transgenic models in the fly using targeted misexpression of human neurodegenerative disease-associated proteins have been established. These include models for HD and other glutamine repeat disorders, noncoding trinucleotide repeat expansions, models of amyloid pathology and tauopathies of relevance to $\mathrm{AD}$, and models studying $\alpha$-synuclein and parkin that pertain to PD. In many instances, robust neurodegeneration is observed in fly models, a distinct advantage as compared with mouse models. In some instances, fly models develop pathological lesions seen in disease, such as inclusion bodies and NFT seen in HD and AD, respectively. However, it is unreasonable to expect fly models to fully recapitulate all features of human disease. Rather, fly models should be viewed as sensitized genetic systems that permit the awesome power of fly genetics to be harnessed in an effort to isolate modifier genes or screen compound libraries at a speed that might be difficult if not impossible to accomplish in mice. Without question, such screens may identify modifiers that are irrelevant to neurodegenerative pathways, but fly models are a good place to start and have begun to provide valuable insight into disease and identify useful compounds. Hopefully, as techniques for analysis improve and become more standardized, fly models will play important roles in our quest to develop cures for neurodegenerative disorders.

Acknowledgments: Thanks to Mel Feany for the ataxin-1 flies, Nancy Bonini for the ataxin-3 and HSPA1 flies, Parsa Kazemi-Esfarjani for the HDJ1 flies, Leslie Thompson and Larry Marsh for the Q108 and htt exon 1 flies, and Huda Zoghbi for the ataxin-1 antibody. This work was supported by grants from the National Institutes of Health (NS002116, NS046489, AG016570, and ES012078) and the American Parkinson's Disease Association (to G.R.J.) and a John J. Wasmuth Post-doctoral Fellowship of the Hereditary Disease Foundation (to T.-K.S.).

\section{REFERENCES}

1. Satterfield TF, Jackson SM, Pallanck LJ. A Drosophila homolog of the polyglutamine disease gene SCA2 is a dosage-sensitive regulator of actin filament formation. Genet 162:1687-1702, 2002.

2. Greene JC, Whitworth AJ, Kuo I, Andrews LA, Feany MB, Pallanck LJ. Mitochondrial pathology and apoptotic muscle degeneration in Drosophila parkin mutants. Proc Natl Acad Sci USA 100:4078-4083, 2003

3. Pesah Y, Pham T, Burgess H, Middlebrooks B, Verstreken P, Zhou $\mathrm{Y}$ et al. Drosophila parkin mutants have decreased mass and cell size and increased sensitivity to oxygen radical stress. Development 131:2183-2194, 2004.

4. Zhang S, Xu L, Lee J, Xu T. Drosophila atrophin homolog functions as a transcriptional corepressor in multiple developmental processes. Cell 108:45-56, 2002.

5. Gunawardena S, Her LS, Brusch RG, Laymon RA, Niesman IR, Gordesky-Gold B, et al. Disruption of axonal transport by loss of huntingtin or expression of pathogenic polyQ proteins in Drosophila. Neuron 40:25-40, 2003.

6. Sharma RP, Chopra VL. Effect of the Wingless (wg1) mutation on wing and haltere development in Drosophila melanogaster. Dev Biol 48:461-465, 1976.

7. Bejsovec A. Wnt pathway activation: new relations and locations. Cell 120:11-14, 2005.

8. The Huntington's Disease Collaborative Research Group. A novel gene containing a trinucleotide repeat that is expanded and unstable on Huntington's disease chromosomes. Cell 72:971-983, 1993.

9. Zoghbi HY, Orr HT. Glutamine repeats and neurodegeneration. Annu Rev Neurosci 23:217-247, 2000.

10. Warrick JM, Paulson HL, Gray-Board GL, Bui QT, Fischbeck KH, Pittman RN, et al. Expanded polyglutamine protein forms nuclear inclusions and causes neural degeneration in Drosophila. Cell 93: 939-949, 1998.

11. Jackson GR, Salecker I, Dong X, Yao X, Arnheim N, Faber PW, et al. Polyglutamine-expanded human huntingtin transgenes induce degeneration of Drosophila photoreceptor neurons. Neuron 21: 633-642, 1998.

12. Cummings CJ, Mancini MA, Antalffy B, DeFranco DB, Orr HT, Zoghbi HY. Chaperone suppression of aggregation and altered subcellular proteasome localization imply protein misfolding in SCA1. Nat Genet 19:148-154, 1998.

13. Chai Y, Koppenhafer SL, Bonini NM, Paulson HL. Analysis of the role of heat shock protein (Hsp) molecular chaperones in polyglutamine disease. J Neurosci 19:10338-10347, 1999.

14. Chai Y, Koppenhafer SL, Shoesmith SJ, Perez MK, Paulson HL. Evidence for proteasome involvement in polyglutamine disease: localization to nuclear inclusions in SCA3/MJD and suppression of polyglutamine aggregation in vitro. Hum Mol Genet 8:673-682, 1999.

15. Suhr ST, Senut MC, Whitelegge JP, Faull KF, Cuizon DB, Gage $\mathrm{FH}$. Identities of sequestered proteins in aggregates from cells with induced polyglutamine expression. J Cell Biol 153:283-294, 2001.

16. Qin ZH, Wang Y, Sapp E, Cuiffo B, Wanker E, Hayden MR, et al. Huntingtin bodies sequester vesicle-associated proteins by a polyproline-dependent interaction. J Neurosci 24:269-281, 2004. 
17. Warrick JM, Chan HY, Gray-Board GL, Chai Y, Paulson HL, Bonini NM. Suppression of polyglutamine-mediated neurodegeneration in Drosophila by the molecular chaperone HSP70. Nat Genet 23:425-428, 1999.

18. Kazemi-Esfarjani P, Benzer S. Genetic suppression of polyglutamine toxicity in Drosophila. Science 287:1837-1840, 2000.

19. Ghosh S, Feany MB. Comparison of pathways controlling toxicity in the eye and brain in Drosophila models of human neurodegenerative diseases. Hum Mol Genet 13:2011-2018, 2004.

20. Ona VO, Li M, Vonsattel JP, Andrews LJ, Khan SQ, Chung WM, et al. Inhibition of caspase-1 slows disease progression in a mouse model of Huntington's disease. Nature 399:263-267, 1999.

21. Chen M, Ona VO, Li M, Ferrante RJ, Fink KB, Zhu S, et al. Minocycline inhibits caspase- 1 and caspase- 3 expression and delays mortality in a transgenic mouse model of Huntington disease. Nat Med 6:797-801, 2000.

22. Hersch S, Fink K, Vonsattel JP, Friedlander RM. Minocycline is protective in a mouse model of Huntington's disease. Ann Neurol 54:841, 2003.

23. Thomas M, Ashizawa T, Jankovic J Minocycline in Huntington's disease: a pilot study. Mov Disord 19:692-695, 2004.

24. Hay BA, Wolff T, Rubin GM. Expression of baculovirus P35 prevents cell death in Drosophila. Development 120:2121-2129, 1994.

25. Hay BA, Wassarman DA, Rubin GM. Drosophila homologs of baculovirus inhibitor of apoptosis proteins function to block cell death. Cell 83:1253-1262, 1995.

26. Sang TK, Li C, Liu W, Rodriguez A, Abrams JM, Zipursky SL, et al. Inactivation of Drosophila Apaf-1 related killer suppresses formation of polyglutamine aggregates and blocks polyglutamine pathogenesis. Hum Mol Genet 14:357-372, 2005.

27. Arrasate M, Mitra S, Schweitzer ES, Segal MR, Finkbeiner S. Inclusion body formation reduces levels of mutant huntingtin and the risk of neuronal death. Nature 431:805-810, 2004

28. Steffan JS, Bodai L, Pallos J, Poelman M, McCampbell A, Apostol $\mathrm{BL}$, et al. Histone deacetylase inhibitors arrest polyglutaminedependent neurodegeneration in Drosophila. Nature 413:739-743, 2001.

29. Ferrante RJ, Kubilus JK, Lee J, Ryu H, Beesen A, Zucker B, et al. Histone deacetylase inhibition by sodium butyrate chemotherapy ameliorates the neurodegenerative phenotype in Huntington's disease mice. J Neurosci 23:9418-9427, 2003.

30. Hockly E, Richon VM, Woodman B, Smith DL, Zhou X, Rosa E, et al. Suberoylanilide hydroxamic acid, a histone deacetylase inhibitor, ameliorates motor deficits in a mouse model of Huntington's disease. Proc Natl Acad Sci USA 100:2041-2046, 2003.

31. Ravikumar B, Vacher C, Berger Z, Davies JE, Luo S, Oroz LG, et al. Inhibition of mTOR induces autophagy and reduces toxicity of polyglutamine expansions in fly and mouse models of Huntington disease. Nat Genet 36:585-595, 2004.

32. Pollitt SK, Pallos J, Shao J, Desai UA, Ma AA, Thompson LM, et al. A rapid cellular FRET assay of polyglutamine aggregation identifies a novel inhibitor. Neuron 40:685-694, 2003.

33. Kazantsev A, Walker HA, Slepko N, Bear JE, Preisinger E, Steffan JS, et al. A bivalent Huntingtin binding peptide suppresses polyglutamine aggregation and pathogenesis in Drosophila. Nat Genet 30:367-376, 2002.

34. Marsh JL, Walker H, Theisen H, Zhu YZ, Fielder T, Purcell J, et al. Expanded polyglutamine peptides alone are intrinsically cytotoxic and cause neurodegeneration in Drosophila. Hum Mol Genet 9:13-25, 2000

35. Kazemi-Esfarjani P, Benzer S. Suppression of polyglutamine toxicity by a Drosophila homolog of myeloid leukemia factor 1 . Hum Mol Genet 11:2657-2672, 2002

36. Higashiyama H, Hirose F, Yamaguchi M, Inoue YH, Fujikake N, Matsukage A, et al. Identification of ter94, Drosophila VCP, as a modulator of polyglutamine-induced neurodegeneration Cell Death Differ 9:264-273, 2002.

37. Feany MB, Bender WW. A Drosophila model of Parkinson's disease. Nature 404:394-398, 2000.

38. Fernandez-Funez P, Nino-Rosales ML, de Gouyon B, She WC, Luchak JM, Martinez P, et al. Identification of genes that modify ataxin-1-induced neurodegeneration. Nature 408:101-106, 2000.
39. Tsai CC, Kao HY, Mitzutani A, Banayo E, Rajan H, McKeown M, et al. Ataxin 1, a SCA1 neurodegenerative disorder protein, is functionally linked to the silencing mediator of retinoid and thyroid hormone receptors. Proc Natl Acad Sci USA 101:4047-4052, 2004.

40. Warrick JM, Morabito LM, Bilen J, Gordesky-Gold B, Faust LZ, Paulson HL, et al. Ataxin-3 suppresses polyglutamine neurodegeneration in Drosophila by a ubiquitin-associated mechanism. Mol Cell 18:37-48, 2005.

41. Steffan JS, Agrawal N, Pallos J, Rockabrand E, Trotman LC Slepko N, et al. SUMO modification of Huntingtin and Huntington's disease pathology. Science 304:100-104, 2004.

42. Lee WC, Yoshihara M, Littleton JT. Cytoplasmic aggregates trap polyglutamine-containing proteins and block axonal transport in a Drosophila model of Huntington's disease. Proc Natl Acad Sci USA 101:3224-3229, 2004.

43. Takeyama K, Ito S, Yamamoto A, Tanimoto H, Furutani T, Kanuka H, et al. Androgen-dependent neurodegeneration by polyglutamine-expanded human androgen receptor in Drosophila. Neuron 35:855-864.

44. Chan HY, Warrick JM, Andriola I, Merry D, Bonini NM. Genetic modulation of polyglutamine toxicity by protein conjugation pathways in Drosophila. Hum Mol Genet 11:2895-2904, 2002.

45. Campuzano V, Montermini L, Molto MD, Pianese L, Cossee M, Cavalcanti F, et al. Friedreich's ataxia: autosomal recessive disease caused by an intronic GAA triplet repeat expansion. Science 271: 1423-1427, 1996.

46. Koob MD, Moseley ML, Schut LJ, Benzow KA, Bird TD, Day JW, et al. An untranslated CTG expansion causes a novel form of spinocerebellar ataxia (SCA8). Nat Genet 21:379-384, 1999.

47. Brook JD, McCurrach ME, Harley HG, Buckler AJ, Church D, Aburatani $\mathrm{H}$, et al. Molecular basis of myotonic dystrophy: expansion of a trinucleotide (CTG) repeat at the $3^{\prime}$ end of a transcript encoding a protein kinase family member. Cell 68:799-808, 1992.

48. Mutsuddi M, Marshall CM, Benzow KA, Koob MD, Rebay I. The spinocerebellar ataxia 8 noncoding RNA causes neurodegeneration and associates with staufen in Drosophila. Curr Biol 14:302-308, 2004.

49. Houseley JM, Wang Z, Brock GJ, Soloway J, Artero R, PerezAlonso M, et al. Myotonic dystrophy associated expanded CUG repeat muscleblind positive ribonuclear foci are not toxic to Drosophila. Hum Mol Genet 14:873-883, 2005.

50. Kremer EJ, Pritchard M, Lynch M, Yu S, Holman K, Baker E, et al. Mapping of DNA instability at the fragile $\mathrm{X}$ to a trinucleotide repeat sequence $p(C C G) n$. Science 252:1711-1714, 1991.

51. Jin P, Zarnescu DC, Zhang F, Pearson CE, Lucchesi JC, Moses K, et al. RNA-mediated neurodegeneration caused by the fragile $X$ premutation rCGG repeats in Drosophila. Neuron 39:739-747, 2003.

52. Tanzi RE, Bertram L. Twenty years of the Alzheimer's disease amyloid hypothesis: a genetic perspective. Cell 120:545-555, 2005.

53. Alzheimer's Disease Collaborative Group. The structure of the presenilin 1 (S182) gene and identification of six novel mutations in early onset AD families. Nat Genet 11:219-222, 1995.

54. Tanzi RE, Vaula G, Romano DM, Mortilla M, Huang TL, Tupler $\mathrm{RG}$, et al. Assessment of amyloid $\beta$-protein precursor gene mutations in a large set of familial and sporadic Alzheimer disease cases. Am J Hum Genet 51:273-282, 1992.

55. Luo L, Tully T, White K. Human amyloid precursor protein ameliorates behavioral deficit of flies deleted for Appl gene. Neuron 9:595-605, 1992.

56. Torroja L, Chu H, Kotovsky I, White K. Neuronal overexpression of APPL, the Drosophila homologue of the amyloid precursor protein (APP), disrupts axonal transport. Curr Biol 9:489-492, 1999.

57. Iijima K, Liu HP, Chiang AS, Hearn SA, Konsolaki M, Zhong Y. Dissecting the pathological effects of human $A \beta 40$ and $A \beta 42$ in Drosophila: a potential model for Alzheimer's disease. Proc Natl Acad Sci USA 101:6623-6628, 2004.

58. Finelli A, Kelkar A, Song HJ, Yang H, Konsolaki M. A model for studying Alzheimer's A $\beta 42$-induced toxicity in Drosophila melanogaster. Mol Cell Neurosci 26:365-375, 2004. 
59. Iwata N, Tsubuki S, Takaki Y, et al. Metabolic regulation of brain A $\beta$ by neprilysin. Science 292:1550-1552, 2001.

60. Greeve I, Kretzschmar D, Tschape JA, Beyn A, Brellinger C, Schweizer M, et al. Age-dependent neurodegeneration and Alzheimer-amyloid plaque formation in transgenic Drosophila. $\mathrm{J} \mathrm{Neu-}$ rosci 24:3899-3906, 2004.

61. Gunawardena S, Goldstein LS. Disruption of axonal transport and neuronal viability by amyloid precursor protein mutations in Drosophila. Neuron 32:389-401, 2001.

62. Stokin GB, Lillo C, Falzone TL, Brusch RG, Rockenstein E, Mount SL, et al. Axonopathy and transport deficits early in the pathogenesis of Alzheimer's disease. Science 307:1282-1288, 2005.

63. Struhl G, Greenwald I. Presenilin is required for activity and nuclear access of Notch in Drosophila. Nature 398:522-525, 1999.

64. Ye Y, Lukinova N, Fortini ME. Neurogenic phenotypes and altered Notch processing in Drosophila Presenilin mutants. Nature 398:525-529, 1999.

65. Francis R, McGrath G, Zhang J, Ruddy DA, Sym M, Apfeld J, et al. Aph-1 and pen-2 are required for Notch pathway signaling, $\gamma$-secretase cleavage of $\beta \mathrm{APP}$, and presenilin protein accumulation. Dev Cell 3:85-97, 2002.

66. Niimura M, Isoo N, Takasugi N, Tsuruoka M, Ui-Tei K, Saigo K, et al. Aph- 1 contributes to the stabilization and trafficking of the $\gamma$-secretase complex through mechanisms involving intermolecular and intramolecular interactions. J Biol Chem 280:12967-12975, 2005.

67. Guo M, Hong EJ, Fernandes J, Zipursky SL, Hay BA. A reporter for amyloid precursor protein $\gamma$-secretase activity in Drosophila. Hum Mol Genet 12:2669-2678, 2003.

68. Lee VM, Goedert M, Trojanowski JQ. Neurodegenerative tauopathies. Аnпи Rev Neurosci 24:1121-1159, 2001.

69. Heidary G, Fortini ME. Identification and characterization of the Drosophila tau homolog. Mech Dev 108:171-178, 2001.

70. Williams DW, Tyrer M, Shepherd D. Tau and tau reporters disrupt central projections of sensory neurons in Drosophila. J Comp Neurol 428:630-640, 2000.

71. Mudher A, Shepherd D, Newman TA, Mildren P, Jukes JP, Squire A, et al. GSK-3 $\beta$ inhibition reverses axonal transport defects and behavioural phenotypes in Drosophila. Mol Psychiatry 9:522-530, 2004.

72. Wittmann CW, Wszolek MF, Shulman JM, Salvaterra PM, Lewis J, Hutton M, et al. Tauopathy in Drosophila: neurodegeneration without neurofibrillary tangles. Science 293:711-714, 2001.

73. Shulman JM, Feany MB. Genetic modifiers of tauopathy in Drosophila. Genet 165:1233-1242, 2003.

74. Mershin A, Pavlopoulos E, Fitch O, Braden BC, Nanopoulos DV, Skoulakis EM. Learning and memory deficits upon TAU accumulation in Drosophila mushroom body neurons. Learn Mem 11:277287, 2004.

75. Jackson GR, Wiedau-Pazos M, Sang TK, Wagle N, Brown CA, Massachi S, et al. Human wild-type tau interacts with wingless pathway components and produces neurofibrillary pathology in Drosophila. Neuron 34:509-519, 2002.

76. Nishimura I, Yang Y, Lu B. PAR-1 kinase plays an initiator role in a temporally ordered phosphorylation process that confers tau toxicity in Drosophila. Cell 116:671-682, 2004.

77. Vila M, Przedborski S. Genetic clues to the pathogenesis of Parkinson's disease. Nat Med 10:S58-S62, 2004.

78. Singleton AB, Farrer M, Johnson J, Singleton A, Hague S, Kachergus J, et al. $\alpha$-Synuclein locus triplication causes Parkinson's disease. Science 302:841, 2003.

79. Auluck PK, Chan HY, Trojanowski JQ, Lee VM, Bonini NM. Chaperone suppression of $\alpha$-synuclein toxicity in a Drosophila model for Parkinson's disease. Science 295:865-868, 2002.

80. Auluck PK, Bonini NM. Pharmacological prevention of Parkinson disease in Drosophila. Nat Med 8:1185-1186, 2002.

81. Auluck PK, Meulener MC, Bonini NM. Mechanisms of suppression of $\alpha$-synuclein neurotoxicity by geldanamycin in Drosophila. J Biol Chem 280:2873-2878, 2005.

82. Pendleton RG, Parvez F, Sayed M, Hillman R. Effects of pharmacological agents upon a transgenic model of Parkinson's disease in Drosophila melanogaster. J Pharmacol Exp Ther 300:91-96, 2002.

83. Yang Y, Nishimura I, Imai Y, Takahashi R, Lu B. Parkin suppresses dopaminergic neuron-selective neurotoxicity induced by Pael-R in Drosophila. Neuron 37:911-924, 2003.

84. Haywood AF, Staveley BE. Parkin counteracts symptoms in a Drosophila model of Parkinson's disease. BMC Neurosci 5:14, 2004.

85. Pesah Y, Burgess H, Middlebrooks B, et al. Whole-mount analysis reveals normal numbers of dopaminergic neurons following misexpression of $\alpha$-synuclein in Drosophila. Genesis 41:154-159, 2005.

86. Kitada T, Asakawa S, Hattori N, Matsumine H, Yamamura Y, Minoshima S, et al. Mutations in the parkin gene cause autosomal recessive juvenile parkinsonism. Nature 392:605-608, 1998.

87. Hattori N, Mizuno Y. Pathogenetic mechanisms of parkin in Parkinson's disease. Lancet 364:722-724, 2004.

88. Von Coelln R, Thomas B, Savitt JM, Lim KL, Sasaki M, Hess EJ, et al. Loss of locus coeruleus neurons and reduced startle in parkin null mice. Proc Natl Acad Sci USA 101:10744-10749, 2004.

89. Goldberg MS, Fleming SM, Palacino JJ, Cepeda C, Lam HA, Bhatnagar A, et al. Parkin-deficient mice exhibit nigrostriatal deficits but not loss of dopaminergic neurons. J Biol Chem 278: 43628-43635, 2003.

90. Itier JM, Ibanez P, Mena MA, Abbas N, Cohen-Salmon C, Bohme $\mathrm{GA}$ et al. Parkin gene inactivation alters behaviour and dopamine neurotransmission in the mouse. Hum Mol Genet 12:2277-2291, 2003.

91. Perez FA, Palmiter RD. Parkin-deficient mice are not a robust model of parkinsonism. Proc Natl Acad Sci USA 102:2174-2179, 2005. 